\title{
NOTAS ETNOBOTÂNICAS EM TERRAS INDÍGENAS MEBENGOKRE
}

\author{
Elias Januário ${ }^{1}$
}

Germano Guarim Neto ${ }^{2}$

Fernando Selleri Silva ${ }^{3}$

\section{INTRODUÇÃO}

Entre os saberes que se aprende desde criança numa comunidade indígena, estão o conhecimento e o respeito para com o meio ambiente local, que ocorre de maneira processual ao longo da formação enquanto indivíduo, através de atividades realizadas no cotidiano, como a preparação das roças, as caçadas, as pescarias, os rituais, a confecção de artesanato, os ritos de passagens, as narrativas míticas, entre tantas outras formas.

Vamos conhecer um pouco sobre o cotidiano do povo indígena Mebengokre, conhecido popularmente pelo nome de Kayapó, sendo a maioria das suas aldeias localizadas às margens do rio Xingu, com distâncias que variam de $50 \mathrm{~km}$ a $150 \mathrm{~km}$ da área urbana do município de Peixoto de Azevedo e São José do Xingu, norte do estado de Mato Grosso, cujo acesso se faz pela BR 163 e BR 322.

O entorno da Terra Indígena Kapôt/Jarina já encontra cercado de fazendas com áreas enormes de pasto para a criação de gado, com casas construídas de alvenaria e com energia elétrica nos imóveis. Seguindo por uma estrada de terra adentra-se em uma área

1 Universidade do Estado de Mato Grosso, Doutor em Educação e Pós-Doutor em Antropologia e Etnobotânica, Aposentado, Rua Maria Martins Paixão, 343, Centro, Chapada dos Guimarães, MT - 78.195-000. Grupo de Pesquisa Memória, Identidade, Cultura Material e Educação Infantil dos Povos Indígenas. Grupo de Pesquisa Flora, Vegetação e Etnobotânica - FLOVET. eliasjanuario@terra.com.br

2 Universidade Federal de Mato Grosso, Doutor em Ciências Biológicas (Botânica), Instituto de Biociências, Departamento de Botânica e Ecologia - Av. Fernando Corrêa da Costa, 2367 - Bairro Boa Esperança. Cuiabá-MT, 78.060-900. Grupo de Pesquisa Flora, Vegetação e Etnobotânica - FLOVET. guarim@ufmt.br

3 Universidade do Estado de Mato Grosso, Doutor em Ciência da Computação, CC/ FACET, Campus Universitário de Barra do Bugres - MT, Bairro São Raimundo, Cx Postal 92, Barra do Bugres, MT, 78.550-000. Grupo de Pesquisa eBDES. Grupo de Pesquisa Educação Superior Indígena. selleri@unemat..br 
de mata fechada com a presença de pequenos animais e pássaros, sinalizando para a proximidade das aldeias. Na maioria das aldeias o acesso só é feito de barco através do rio Xingu ou por via aérea em pequenas aeronaves.

Conforme Gutierres; Januário (2015), a poluição do ar tem sido uma das grandes preocupações dos indígenas, pois afeta diretamente a saúde da comunidade. $O$ fato das Terras Indígenas fazerem divisa com fazendas de plantação de soja, milho, algodão, entre outros, o agrotóxico utilizado nesses cultivos chega até as aldeias através do vento ou mesmo da água provocando desastres irreparáveis à saúde dos moradores das comunidades indígenas atingidas.

A chegada na aldeia revela as características tradicionais deste povo, começando pela disposição de forma circular das malocas, construídas de madeiras da região e cobertas com palha de bananeira brava. No centro do círculo de casas é possível avistar a casa dos homens, onde são realizadas as reuniões culturais e tomadas as decisões políticas e administrativas relacionadas ao dia a dia da comunidade. Em uma das aldeias, denominada de 'Kremoro', vivem mais de quinhentas pessoas, distribuída em cerca de quarentas casas, formando núcleos familiares de quinze a vinte pessoas por habitação.

Fazendo parte da estrutura da maioria das aldeias, é possível avistar uma escola, um posto de saúde, um campo de futebol e uma pista de pouso.

Em meio a essa estrutura e organização social, as roças são individuais, ou seja, cada núcleo familiar cuida da sua produção de alimentos, que vai da limpeza da área a ser cultivada, da plantação, manutenção e colheita das diferentes qualidades de alimentos, como mandioca, banana, abacaxi, batata doce, mamão, cará, miIho, melancia, abóbora, amendoim, cana de açúcar, entre outras.

Nas proximidades das aldeias existem vários córregos, que são amplamente utilizados pela população local para tomar banho, para pescar diversos tipos de peixes, inclusive com o uso do timbó no período da seca, além das atividades de lazer das crianças e dos adolescentes.

As concepções cosmológicas estão muito presentes no dia a dia dos indígenas, isto é, o entendimento mítico da origem do 
povo, dos objetos e seres vivos da natureza, bem como da relação com o mundo sobrenatural, faz parte da formação e da identidade enquanto indivíduo e enquanto grupo social culturalmente diferenciado.

As cosmologias indígenas representam modelos complexos e integrados dos quais faz parte a sociedade humana. Os mitos são fontes de informação sobre a concepção do universo, incluindo temas sobre a criação do mundo, a origem da agricultura, as relações ecológicas entre animais, plantas e outros elementos (RAMOS, 1994).

Diante de tamanha relevância do tema, destaca-se o mito de origem do povo Mebengokre, que está relacionado ao encontro de um ancestral com um tatu, que seguindo o animal pelo buraco feito por ele, encontra outro mundo, cheio de plantas e animais, para onde todos os indígenas de sua etnia passaram a viver em harmonia e equilíbrio com esse ecossistema. Ressaltamos que trata de uma forma simples e resumida do mito de origem, que originalmente consiste de uma narrativa longa e cheia de detalhes, contada oralmente na língua materna pelos anciãos, a exemplo de outros mitos de origem como o do milho, da lua, de alguns animais e objetos, entre tantos outros.

Conforme Januário; Guarim Neto (2013), os conhecimentos relacionados com a natureza são transmitidos desde muito cedo de geração para geração, por meio da oralidade, fazendo com que esses povos passem a ter uma relação diferenciada com o meio ambiente que o circunda. Os saberes que essas comunidades possuem acerca da natureza são tão diversos quanto a humanidade. Da convivência surgem situações de aprendizagem e de conhecimentos. Os saberes nas comunidades tradicionais têm uma importância fundamental na vida social do indivíduo, onde essa diversidade de experiência é compartilhada dando sentido e identidade para a pessoa. Por meio do aprendizado cotidiano acerca da natureza, que é a verdadeira educação informal, as experiências são compartilhadas e os fenômenos da natureza e do mundo apreendidos pelos indivíduos.

Segundo Crepaldi; Januário (2013), as práticas culturais indígenas não são estáticas, pelo contrário, elas são, como qualquer outra cultura, dinâmicas. Assim, transformam-se ao longo do tempo. Por 
outro lado, é inegável que as mudanças decorrentes do contato com a sociedade não índia podem, muitas vezes, alcançar escalas preocupantes. As comunidades tradicionais, de uma maneira geral, estão sofrendo pressões econômicas e culturais que, de certa forma, por um processo gradual de ressignificação cultural, estão transformando uma infinidade de conhecimentos acumulados durante séculos. Entre eles encontram-se a sua forma de se relacionar com a natureza e com os demais membros da comunidade através de códigos de significados que a própria comunidade estabelece, como nos explica GEERTZ (1989).

Brandão (1994) elucida que o conhecimento das comunidades tradicionais pode auxiliar a minimizar os problemas sociais e ambientais que o mundo atualmente enfrenta, devido o relacionamento mais respeitoso com o meio ambiente, entendido por eles como parte significativa do seu sistema cultural e elemento necessário a sobrevivência da comunidade.

Para Gallois (2011), refletir acerca das questões socioambientais significa estar voltado à valorização das formas de manejo tradicionais, à conservação dos recursos das Terras Indígenas que para o índio é o que tem garantido a qualidade de vida no dia a dia da maior parte das aldeias. A autora acrescenta que, as experiências, agora, têm um foco diferenciado no sentido de construir alternativas de futuro a partir da complementação entre práticas tradicionais e algumas tecnologias dos não índios.

Diante dessa problemática, Crepaldi; Januário (2013) explicam que se não forem estabelecidas políticas públicas com projetos que minimizem esse cenário, gradativamente o ecossistema será destruído, eliminando a biodiversidade, tendo assim a falta de peixes, de animais para a caça, escassez de sementes para o cultivo, além de causar também um aumento nas espécies ameaçadas de extinção tanto animais quanto vegetais. Acabando com ela, acaba também com povos que vivem nela e dela.

\section{CONSIDERAÇÕES METODOLÓGICAS}

Os dados foram obtidos a partir da própria experiência dos autores em atuar com a gestão da Educação Escolar Indígena na UNEMAT até o ano de 2012 e a partir de pesquisas realizadas por 
inúmeros projetos de ensino, pesquisa e extensão. Dentro de uma perspectiva qualitativa e etnográfica (Zanten, 1995; André, 1999), com contornos de um estudo de caso fundamentado metodologicamente em Lüdke; André (1986), Santos (2005), Zanten (1995) e Geertz (1989), com uma equipe composta por professores pesquisadores, estudantes de mestrado, estudantes de graduação e estudantes dos cursos de licenciatura indígena, pesquisamos os aspectos relacionados ao meio ambiente das comunidades indígenas. Os dados da pesquisa foram obtidos através de observação participante (Giroux, 1995; Meihy, 1996), utilizando-se de visitas às aldeias, entrevistas semiestruturadas, anotações em diários de campo, gravações em áudio e registro fotográfico.

As reflexões sobre etnobotânica, diversidade cultural e sustentabilidade possuem o suporte teórico de GUARIM NETO (1987; 1996; 2006; 2008; 2010), FARIA (2003), RAMOS (1994), JANUÁRIO et al. (2009a) e BRANDÃO (1994).

A entrevista é um dos principais instrumentos de coleta de dados usado nas pesquisas qualitativas, desempenhando papel importante nos estudos científicos. Segundo Lüdke; André (1986), essa técnica "permite a captação imediata e corrente da informação desejada, praticamente com qualquer tipo de informante e sobre os mais variados tópicos". De acordo com Moreira (2002), a entrevista pode ser definida como "uma conversa entre duas ou mais pessoas com um propósito específico em mente". As entrevistas são aplicadas para que o pesquisador obtenha informações que provavelmente os entrevistados têm. Nas entrevistas semiestruturadas há o momento das perguntas anteriormente determinadas, podendo ser as respostas relativamente livres.

A observação participante traz informações inerentes ao foco da pesquisa, uma vez que o pesquisador adentra no universo do campo de pesquisa, possibilitando o registro de uma "série de fenômenos de grande importância que não podem ser registrados através de perguntas ou em documentos quantitativos, mas devem ser observados em sua plena realidade" (MALINOWSKI, 1975).

A pesquisa contou com a participação efetiva de indígenas que estavam cursando e egressos dos cursos de Graduação e Pós-Graduação (lato sensu). Este fator foi primordial na integração dos professores indígenas em formação e dos egressos como sujeitos 
desse processo de construção da avaliação processual da formação de professores indígenas em Mato Grosso.

\section{RESULTADOS E DISCUSSÃO}

As principais plantas nativas de conhecimento, uso e consumo dos índios Mebengokre, que compõe a flora local, são a banana brava, palmeira inajá, ingá, açaí, bacaba, macaúba, embaúba, palmeira babaçu, buriti, mangaba, pequi e jatobá do cerrado. Existem outras, que não tem tradução para a língua portuguesa como rojkrãtire, màtu, kamôt, abiuna, kamôttire goloza, gràdjare, gradjakaàk, mamui, mrê, entre tantas.

Ao trabalharmos com os povos Mebengokre, nos foi revelado uma impressionante riqueza de tradições e costumes que são transmitidas de geração para geração, dentre esses saberes destaca-se a questão da etnobotânica, que aparece envolta em mitos, ritos e tradições. Isso é recorrente na maioria das etnias do estado do Mato Grosso, muitas delas, ricas em mitos a respeito da origem dos alimentos, as restrições alimentares, bem como os rituais para o preparo de alguns alimentos. No entanto, com o passar do tempo esses conhecimentos estão sendo ressignificados e muito pouco registrados, isso faz com que saberes ainda não estudados sejam perdidos, saberes esses que poderiam trazer benefícios para toda sociedade brasileira (JANUÁRIO et al., 2009b).

Dessas plantas, algumas merecem destaque pela sua importância na dieta dessas comunidades, entre elas podemos destacar a banana brava, cuja fruta as mulheres buscam na mata, em locais próximos aos córregos e preparam a fruta descascando as bananas e socando no pilão até formar uma massa homogênea, que depois é assada enrolada em folhas de pacova, sendo consumido com beiju e carne de animais da região. Outra forma de preparar a banana brava é na forma de chicha, muito consumida durante os rituais e festas.

Outra planta nativa da região muito usada é o ingá, cuja polpa da fruta é muito apreciada como complemento alimentar e sua madeira usada como lenha nas fogueiras no interior das casas para aquecer durante a noite. Já a palmeira inajá tem outras utilidades além da polpa do fruto como alimento, da castanha é obtido óleo 
para passar no cabelo para ficar com brilho e proporcionar uma cor preta, a palha é usada na cobertura de casas. Os palmitos obtidos destas palmeiras são cortados pelas mulheres em pequenos pedaços e socados com carne de animais caçados pelos homens da aldeia, sendo uma alimentação tradicional deste povo.

Segundo DIEGUES (1998):

“[...] grande parte das florestas tropicais e outros ecossistemas ainda não destruídos pela invasão capitalista é, em grande parte, habitada por tipos de sociedades diferentes das industrializadas, isto é, por sociedades de extrativistas, ribeirinhos, grupos e nações indígenas. Muitas delas ainda não foram totalmente incorporadas à lógica do lucro e do mercado, organizando parcela considerável de sua produção em torno da autossubsistência. Sua relação com a natureza, em muitos casos, é de verdadeira simbiose, e o uso dos recursos naturais só pode ser entendido dentro de uma lógica mais ampla de reprodução social e cultural, distinta da existente na sociedade capitalista".

As folhas de palmeiras como o inajá, tem ainda uma utilidade muito importante em rituais quando morre uma pessoa, bem como nas festas tradicionais como 'mebymybiôk', 'kryrykango', 'takàk', onde as mulheres e as crianças pintam o rosto e o corpo com tinta obtida da mistura do sumo do jenipapo com o pó de carvão, usando pequenas tiras de madeira obtida dos talos de inajá, que são usados como instrumento para fazer as pinturas corporais e faciais. A palmeira inajá também está inserida no universo das crianças, na medida em que de seu caule são feitas pequenas flechas onde os meninos exercitam a atividade de caçadores, flechando pequenos peixes, insetos e anfíbios. Um dos anciãos em entrevista ressaltou a importância ambiental, social e cultural da palmeira inajá, ao nos explicar essa prática cultural de formação das crianças que tem sido passada ao longo de gerações entre os Mebengokre.

Outra planta nativa é o 'manui', que não tem tradução para a língua portuguesa, o seu fruto é consumido depois de assado, devido um tipo de leite que é expelido das frutas quando partida, que provoca queimadura na boca se for consumido sem levar antes ao fogo. Essa planta tem seus frutos coletados no período que corresponde ao mês de dezembro, na região de mata 
fechada, em lugares úmidos, sendo apenas os frutos utilizados pelos indígenas, que coletam o "manui" sem precisar cortar ou derrubar a planta.

De acordo com Beltz; Januário (2013), preservar a natureza em comunidades indígenas é algo que se aprende muito cedo na vida, à medida que as crianças acompanham os adultos às roças e tomam parte nas tarefas cotidianas. E quem se acostuma a plantar, dificilmente deixa de exercer tal atividade, pois aprende que cultivando a roça irá colher os frutos que a terra, tão sagrada para si, fornecera para a sua sobrevivência. As práticas culturais em relação aos mitos sobre as roças ou alimentos indígenas variam muito de uma etnia para outra, mas o que é certo é que seja qual for a etnia indígena, as crianças aprendem desde cedo o valor do trabalho através do cultivo dos alimentos nas roças e aprendem também a importância de fazer de forma que não prejudique demasiadamente o meio ambiente local.

A macaúba, planta bem popular em áreas indígenas e regiões urbanas, típica de áreas de cerrado, é muito apreciada pelas crianças pelo sabor adocicado de seus frutos, coletados manualmente, consumido "in natura" assado no fogo. Já a embaúba, consiste numa planta nativa encontrada em três espécies, na região de floresta mais densa, apenas uma dessas espécies tem seu fruto usado na alimentação pelos indígenas, que a denominam de "atuwyrykrãkre". Das outras duas espécies de embaúba utilizam suas folhas como lixa durante a produção de bordunas, arcos, flechas, cachimbos e diversos artesanatos. Outra particularidade da embaúba é a utilização das suas raízes, de onde é extraído um tipo de líquido semelhante a água, muito nutritivo, que é dado para os bebês tomarem.

De acordo com estudos realizados por Gutierres e Januário (2014), as comunidades indígenas são representantes de generosas fontes de riquezas naturais como madeira, minério, borracha, castanha, entre outros. Os biomas mato-grossenses também contemplam grande riqueza cultural que compreende o conhecimento tradicional do manejo desses recursos naturais com a preocupação em não provocar sua escassez. Mas apenas os cuidados dos povos que habitam e têm a sensibilidade de preservar os biomas não são suficientes para protege-los. 
Poderíamos fazer referência a dezenas de outras plantas nativas, usadas por essa comunidade indígena. No entanto, o objetivo é mostrar a existência e a prática ainda sendo usada pelos indígenas, a exemplo das gerações anteriores, mantendo assim os conhecimentos tradicionais e a identidade enquanto povo indígena que valoriza a relação entre ser humano e a natureza.

\section{CONSIDERAÇÕES FINAIS}

Distante de pretensões conclusivas, porém de direcionamento no sentido do enriquecimento das discussões sobre a questão da etnobotânica em aldeias indígenas, particularmente entre os Mebengokre, reiteramos, com base nas reflexões teóricas efetuadas e na análise das informações proporcionadas pelos indígenas, a necessidade de dar maior ênfase em temáticas como essa. As alterações no meio ambiente têm acontecido muito rapidamente e as comunidades indígenas têm necessitado de um suporte no sentido de mais informações sobre como lidar com essas mudanças.

A maneira como os indígenas sobrevivem hoje, vivendo dispersos em pequenos grupos, com privação de terras, em disputas pela demarcação dos seus territórios, lutando pela ampliação das áreas anteriormente demarcadas, resistindo às mudanças ambientais e culturais a que são submetidos ou adaptando-se de alguma maneira aos hábitos da sociedade envolvente, são retratos dos indígenas na atualidade, que vêm, há muito tempo, perdendo qualidade de vida.

Essas dificuldades mencionadas ao longo deste texto, aliadas a ocupação de áreas inadequadas para o cultivo de roças, para a coleta de frutos e para a prática da caça e da pesca, implicam na dificuldade que os indígenas encontram em manter seu jeito de ser, que passa pela religião, pelo cultivo e consumo de alimentos sagrados e pelas transformações que estão ocorrendo em suas aldeias.

A realidade em que se encontra atualmente grande parte dos povos indígenas do Brasil ameaça a diversidade cultural existente no país. Tal situação acresce ainda de um processo de erosão genética (perda da biodiversidade) manejada há tempos pelos povos indígenas. De um lado, povos tradicionais em busca da sobrevivência, dignidade, pelo reconhecimento de sua cultura e para manterem as matas nativas, fontes de medicamentos e alimentos, pois a terra 
representa para essa população algo muito maior, uma vez que se veem como parte integrante da mesma e da natureza. Por outro lado, grandes latifundiários cujo objetivo principal é o "progresso" de uma região, e para isso, necessário o desmatamento e transformação de paisagens naturais em campos limpos de monoculturas como as pastagens e os grãos.

Uma questão relevante e lamentável para ser pontuada, trata-se das consequências das alterações na flora que vem ocorrendo no cotidiano das comunidades indígenas, proporcionando desdobramentos como a poluição do ar e dos rios, desmatamento, lixo, extinção de animais, das plantas, entre outros, que consequentemente, se refletem negativamente nas práticas culturais, esportivas, produção de artesanatos, festas tradicionais e rituais. A formulação de políticas públicas que atuem no sentido de minimizar esse cenário torna-se imprescindível para as comunidades indígenas nos dias atuais.

\section{REFERÊNCIAS}

ANDRÉ, M. E. D. A. Etnografia da prática escolar. São Paulo: Editora Papirus, 1999. AUZANI, S. C. S.; GIORDANI, R. C. F. Inter-relação entre espaço físico, modo de vida MBYÀ- GUARANI e alimentação na perspectiva da segurança alimentar: reflexões sobre a área indígena Araçá-í em Piraquara - PR. Espaço Ameríndio, Porto Alegre, v. 2, n. 1. 2008.

BELTZ, L.; JANUARIO, E. Roças Indígenas em Mato Grosso, Educação Ambiental e Sustentabilidade. Cuiabá: Instituto Merireu Editora, 2013.

BRANDÃO, C. R. Somos as águas puras. Campinas, SP: Papirus, 1994.

CREPALDI, G. B.; JANUARIO, E. Alimentação indígena em Mato Grosso: Educação Ambiental e Prática Cultural. Cuiabá: Instituto Merireu Editora, 2013.

DIEGUES, A. C. O Mito Moderno da Natureza Intocada. São Paulo: Editora Hucitec, 1998.

FARIA, I. F. Território e Territorialidades indígenas do Alto Rio Negro. Manaus: Editora da Universidade Federal do Amazonas, 2003

GALLOIS, D. T. Terra Indígena Wajãpi: da demarcação às experiências de gestão territorial. São Paulo: lepé, 2011

GEERTZ, C. A Interpretação das Culturas. Rio de Janeiro: Zahar, 1989

GIROUX, H. A. "Praticando estudos culturais nas faculdades de educação", in: SILVA, T. T. (org.). Alienígenas na sala de aula: uma introdução aos estudos culturais em 
educação. Vozes: Petrópolis. 1995.

GUARIM NETO, G. Plantas utilizadas na medicina popular do Estado de Mato Grosso. Brasília: CNPq: Assessoria Editorial, 1987.

GUARIM NETO, G. Plantas Medicinais do Estado de Mato Grosso. Brasília: ABEAS/ UFMT/IB/DB, 1996.

GUARIM NETO, G. O saber tradicional pantaneiro: as plantas medicinais e a educação ambiental. Rev. Eletrônica Mestrado Educação Ambiental, v.17, Cuiabá: UFMT, 2006.

GUARIM NETO, G.; CARVALHO, J. V. F. (Orgs.). Biodiversidade matogrossense. Cuiabá: Carlini \& Caniato, 2010.

GUARIM NETO, G.; MACIEL, M. R. A. O saber local e os recursos vegetais em Juruena, Mato Grosso. Cuiabá: Entrelinas/EdUFMT, 2008

GUTIERRES, S. R.; JANUARIO, Elias. Territórios Indígenas em Mato Grosso: Dimensão Ambiental e Educação Escolar. Cuiabá: Instituto Merireu Editora, 2014. JANUARIO, E.; GUARIM NETO, G. Medicina Indígena: Percepção e Conhecimento sobre Plantas Medicinais em Comunidades Indígena de Mato Grosso. Cuiabá: Instituto Merireu Editora, 2013.

JANUÁRIO, E.; SELLERI, F.; TRONCARELLI, M.C.; VANUCCI, M.P.F.; ZORTHÊA, K.S. (Orgs.). Território Indígena. Barra do Bugres/MT: UNEMAT, 2009a.

JANUÁRIO, E.; SELLERI, F.; TRONCARELLI, M.C.; VANUCCI, M.P.F.; ZORTHÊA, K.S. (Orgs.). Culinária Indígena. Barra do Bugres: UNEMAT, 2009b.

LÜDKE, M.; ANDRÉ, M. E. D. A. Pesquisa em Educação: abordagens qualitativas. São Paulo: EPU, 1986.

MALINOWSKI, B. "Objetivo, método e alcance desta pesquisa", in: GUIMARÃES, A. Z. (Org.). Desvendando máscaras sociais. Rio de Janeiro: Francisco Alves, 1975.

MEIHY, J. C. S. B. Manual de história oral. São Paulo: Edições Loyola, 1996.

MOREIRA, D. A. 0 método fenomenológico na pesquisa. São Paulo: Pioneira Thomson, 2002.

RAMOS, A. R. Sociedades Indígenas. São Paulo: Editora Ática, 1994.

RAMOS, P. R.; JANUARIO, E. Agricultura Indígena: O Sistema Agrícola Praticado entre os Tapirapé. Cuiabá: Instituto Merireu Editora, 2015.

SANTOS, I. E. Manual de Métodos e Técnicas de Pesquisa Científica. 5.ed. Niterói, RJ: Editora IMPETUS, 2005.

ZANTEN, A. H. V. "Abordagens Etnográficas em Sociologia da Educação: escola e comunidade, estabelecimento escolar, sala de aula", In: FORQUIN, J.-C., (org.). Sociologia da Educação. Petrópolis: Vozes, 1995. 